\title{
MODELING OF PROPERTY MANAGEMENT PROCESS AT TERRITORIAL LEVEL
}

\author{
Vladimir Viktorovich Bredikhin ${ }^{1 *}$, Natalia Bredikhina ${ }^{1}$, Valeriy Ezerskiy ${ }^{2}$ \\ ${ }^{1}$ Southwest State University, Kursk, Russian Federation \\ ${ }^{2}$ Bialystok University of Technology, Bialystok, Poland
}

The multivariance of problem-solving techniques of organizing real estate management in the investment and construction complex at the territorial level objectively leads to the need to develop a model designed for the rational resolution of "tension nodes". Such a model can be the methods and tools of designing management technology, or rather one of its areas - technology for solving situational management problems. The article deals with the methodological problems of real estate management technology from the perspective of situational planning; it provides an analysis of the basic principles for the development of technological solutions to management problems and it gives the authoring details.

Key words: territorial investment and construction complex, real estate, project, situational planning, principles of situational planning technology

\section{INTRODUCTION}

The main method of organizing the work of the territorial investment and construction complex (TICC) [1] is the project management method, in accordance with which all the activities of the system participants must be subordinate to the goals of preparing and implementing specific projects related to the management of real estate, with the given results for reconstruction, repair, construction, commissioning and operation of the facility. It means that the objects of management are projects and investment projects in the case of significant changes and modernization of real estate. Accordingly, the technology and organization of work should be based on the composition and sequence of work on preparation and implementation of projects (including investment), taking into account the characteristics of various phases of life cycle [2, 3, 12].

Regardless of the type of project, all of them are carried out in accordance with the following universal sequence of work within a single technological cycle.

The projection of modules for managing specific real estate objects requires compliance with at least the following requirements [4]:

1. Need to consider complex multi-variable relationships, as a consequence of the specifics of management object used by residents with various interests, ambitions, plans, incomes, etc.

2. Taking into account the nonlinearity of dependencies between variables, expressed, for example, in a completely incomparable level of costs to maintain a normal functional mode at objects of different classes.

3. Consideration of various possibilities and ways to solve problems of organizational management, bearing in mind the property of equifinality which is objectively inherent in economic processes in a market economy.

4. Taking into account the dynamics of operating conditions, reflecting not only objectively determined changes and price factors, but also fashion, tastes and preferences of real estate users.

\section{Situational planning in the development of managerial decisions}

The multivariance of problem-solving techniques of organizing real estate management objectively leads to the need to develop a model designed for the rational resolution of "tension nodes". Such a model can be the methods and tools of designing management technology, or rather one of its areas - technology for solving situational management problems $[5,6.7,8]$.

The complexity of the operational chains of situational management processes, the set of signs and types of situations, the possibility of the latter occurring at each stage of management in each subsystem of the external and internal TICC environment, in each component of this environment, in the interaction of the components, leads to an extremely large dimension of the development and implementation task in practice, technologies for solving situational management problems. Therefore, the solution of such a problem can be carried out using complex information systems.

As practice shows, the situational approach to the development of managerial technology is effective only if there is:

- a classifier of situations specific to this company and its production program;

- a set of procedures with the help of which the control 
system is able to respond to the situation satisfactorily, from the point of view of production and commercial interests and the goals set before it;

- selection criteria for a management strategy obtained by expert or other methods.

The analysis allows us to offer one of the possible options with the following list of problems that can be solved when researching and developing technology for solving situational problems of real estate management, shown in Fig. 1.

Practice shows that it is necessary to develop not one common, but a set of management technologies that correspond not only to the formal (by their origin) and substantive features of the situation, but also to their di-

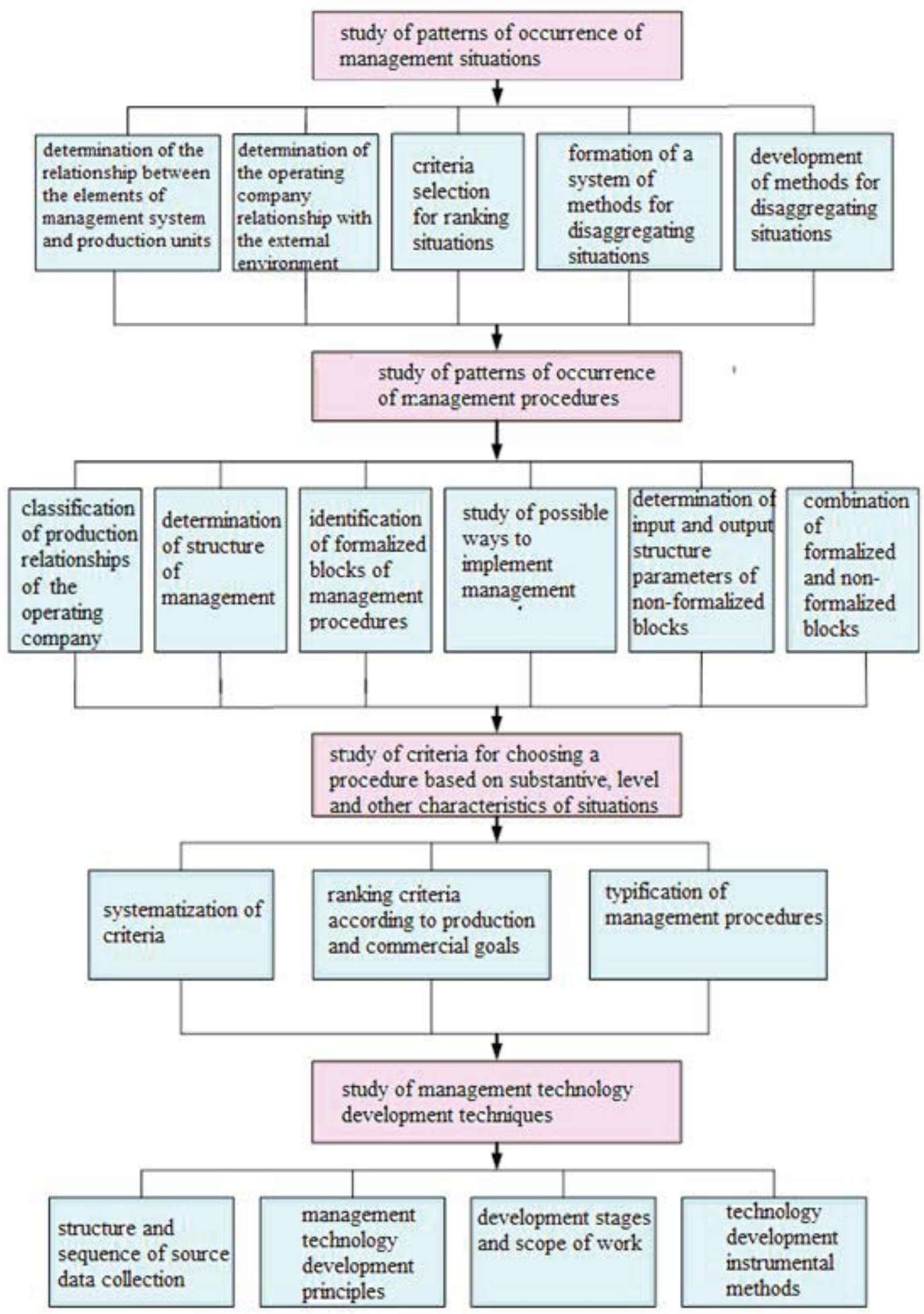

Figure 1: Methodological problems of technology development real estate management solutions 
versity within the framework of the three TICC functioning modes $[9,10,13]$ : implementation of a given program; organization development, transients. Obviously, a certain technology is also peculiar to resolving those situations which, not being resolved on time, go into a class of more complex ones, or the need for resolution of which disappears over time. Moreover, within the framework of each technology characteristic of a particular situation, there are local technological processes through which information processes are carried out (information processing, its fixation, etc.) and decisions and impacts are developed (management, motivation, etc.).

\section{Principles of developing technological solutions to control problems}

It should be noted that not every, even the most advanced management technology can be introduced into economic activity due to the limited available labor and material resources. Therefore, it is important that the technology for solving situational management problems meets the requirements and limitations imposed by management, the requirements of comprehensive solutions, resources saving, etc. At the same time, its development should be guided by certain principles that are determined by the general requirements for the management system, including the management technology as a whole.

As for the principles of developing organizational and technological solutions, it is proposed to adhere, first of all, to the principle of efficiency. As you know, the time intervals of management process are determined by production technologies (derivatives of the main forms of real estate reproduction) and parameters of changing the structure of real estate needs. Moreover, if the control system operates more slowly than the situation arises in connection with the production process, it does not have time to respond to deviations. In this sense, we should talk about the following principles:

first, the principle of efficiency, that is, not a complete synchronization of production and management technologies, but the advancing of the latter;

second, the principle of sustainability, bearing in mind the possibility of changing production specialization, restructuring the real estate portfolio. The frequency of changes may vary, and the technology is sustainable;

third, the principle of regulation, reflected in the charter, regulations, instructions, legislative acts, indicators, contracts, etc. In other words, the regulation of technology should reflect the accepted norms and rules of managing;

fourth, the principle of profitability, which predetermines the requirement of saving all types of resources in solving not only specific practical problems of managing residential real estate, but also forecasting, analytical, accounting, control and other management tasks.

The combination of these principles is a difficult task. An analysis of the activities of territorial specialized compa- nies shows that, for example, an extremely stable technology is neither operational nor economical, although it is strictly regulated $[11,14]$. With its extreme profitability, stability and efficiency in the implementation of control processes are not ensured. Strictly regulated technology is far from always stable.

In connection with the foregoing, using probabilistic methods, it is advisable to try to calculate the rank of each principle for a production organization and its management system.

The development of technology for solving situational management problems is a cyclical process. The non-additivity of the principles requires the analysis of the effectiveness of technology projects based on each of them.

All principles can be taken into account only by analyzing the single, double and other influences of each of them. In practice, this can be done, taking into account the first priority principle and reassessing the result of its use in the transition to the next principle (Fig. 2). In this case, a rational combination of control technology parameters can be achieved.

Each of the above principles for the development of management technology can be detailed.

The principle of efficiency is manifested in the typification of management procedures; the use of rational techniques for performing management operations; enlargement of operations and their blocks; mechanization and automation of their implementation; rational organization of workflow.

The principle of sustainability consists in the interchangeability of blocks of management procedures depending on changes in the signs of situations; unified structure of the information base; use of a single information carrier; the use of multifunctional technical controls; advanced training of management personnel.

The principle of regulation covers compliance with hierarchical and functional relationships of the management system; stability and quality of economic relations; legal regulation; regulation of procedures and operations.

The principle of profitability consists in saving labor and material resources; the use of management personnel in accordance with their qualifications; evenly loaded managerial staff; development of universal programs and techniques.

\section{CONCLUSION}

Situational planning is not a guaranteed recipe for successful management in real estate, but you should not refuse it. Under the conditions when the competition mechanism operates on the market, when the plans themselves often compete among themselves, not all, even the most advanced management technologies can be introduced into economic activity due to the limited available labor and material resources. 


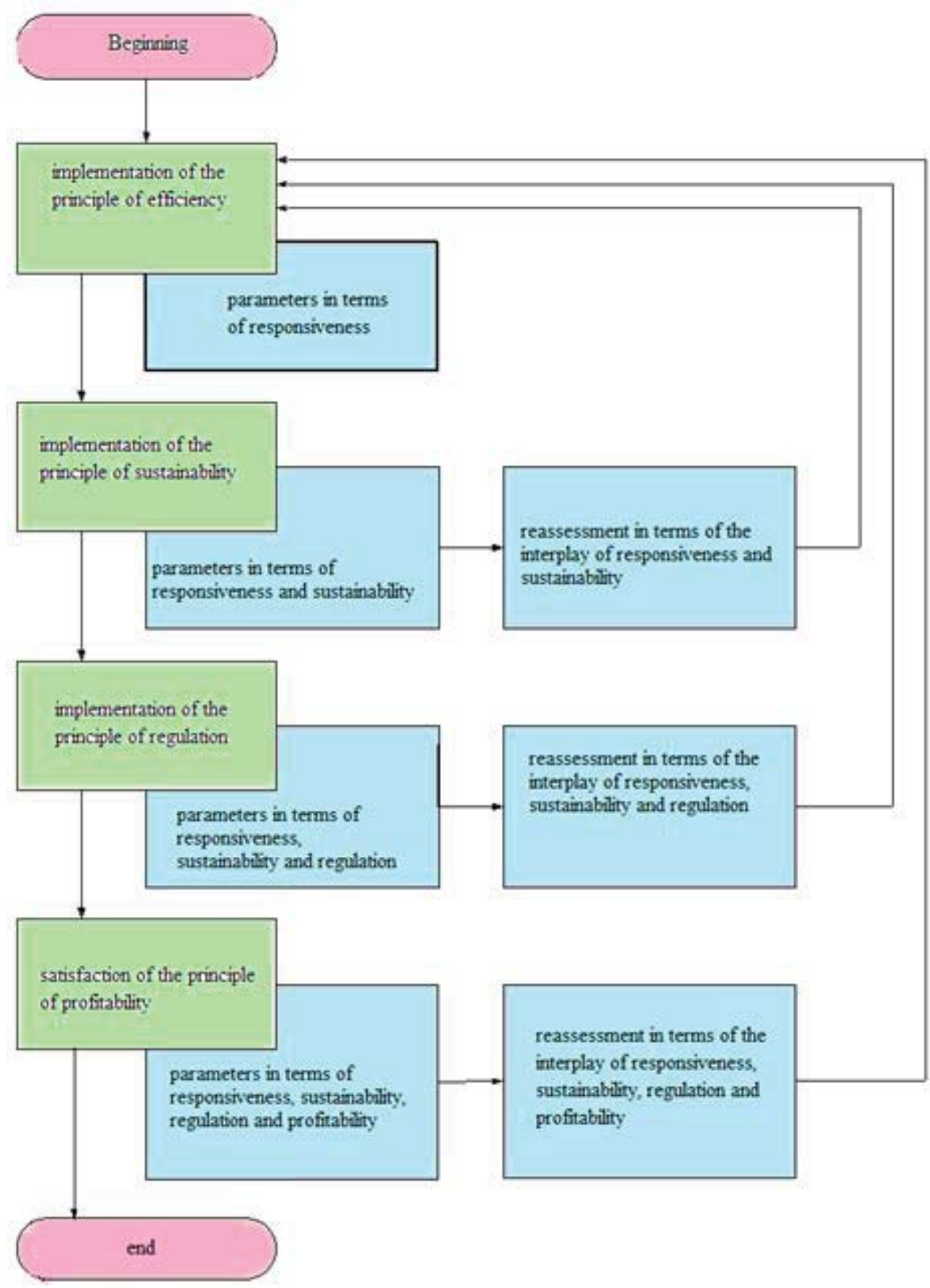

Figure 2: Interconnection of technology development principles situational management

At the same time, the development of the management model should be guided by certain principles, which are determined by the general requirements for the management system. It is possible to take into account all the principles only by analyzing the single, double and other influences of each of them, and their detailing. In practice, this can be done, taking into account the priority principle and reassessing the result of its use in the transition to the next principle. In this case, a rational combination of control technology parameters can be achieved.

\section{REFERENCES}

1. Viktorovich, B. V., Vladimirovna, B. N., \&Yurievna, A. I. [2019]. Analysis of the development process of the territorial productive and technological potential of the region's construction organizations. Journal of Applied Engineering Science, 17(3), 395-399.

2. Bredikhin V.V. [2012]. Analysis of existing methods for solving the problem of reproduction of residential real estate objects. Kursk. p.112.

3. Bredikhin V.V., Shleenko A.V., Bredikhina N.V. [2016]. Development of production and technical potential of the region's construction industry. Kursk. p.114. 
4. Kamenskikh, N.A. [2018]. Regional management and territorial planning: strategic partnership in the system of regional development. Moscow. p. 407.

5. Schedler A. Mapping contingency. In: I. Shapiro, S. Bedi (Eds.). [2007]. Political contingency: studying the unexpected, the accidental, and the unforeseen, New York, p. 56.

6. Webb G., Chevreau F. [2006]. Planning to improvise: the importance of creativity and flexibility in crisis response. International Journal of Emergency Management, vol. 3, 1. p. 68.

7. Zub A.T. [2017]. Situational planning as a tool for crisis management. Economy and management of national economy 6(151), 25-29.

8. Merkulova, YU. V. [2015]. Situational and strategic planning in the economy. Simulation of optimal strategies and programmes. Moscow, p.464.

9. Bredikhin V.V. [2016]. Strategy for the development of residential real estate in the region. Region: systems, economics, management, 3(34), 51-57.

10. Bredikhin V.V. [2013]. Methodology for the formation and development of the total production and technical potential of the city and region. Kursk, p.122.
11. Vladimirovna-Bredikhina, N. [2017]. Basic principles of production-and-technical potential capacity formation in the construction industry of a region. Journal of Applied Engineering Science, 15(4), 495-497.

12. Sergeevich, Y. V., Evgenievna, S. N., Gennadievna, P. E., Vladimirovna, B. N., \& Emmanuel, S. [2019]. To the question of improving energy-saving and environmental characteristics of urban buildings. Journal of Applied Engineering Science, 17(4), 550-554.

13. Vladimir Ezhov, Natalya Semicheva, Valeria Kretova, Vasily Amelin. [2015]. Enhancement of Reliability and Efficiency of Heat Recovery of Off Gases and Ventilation Discharge. Procedia Engineering 117, 94-101.

14. N.V. Bakaeva, A.V. Shleenko, S.N. Volkova, E.E. Sivak, M.I. Pshkova. [2017]. Nonlinear interaction and their modeling in socio-ecological systems. Izvestiya Vysshikh Uchebnykh Zavedenii. Seriya Teknologiya Tekstilno i Promyshlennosti, 1(367), 24-29. 